\title{
The Impact of Job Stress and Self-Efficacy on Job Burnout Dimensions
}

\author{
Abdelmohsen A. Nassani $^{*} \quad$ Rana M. Almusad ${ }^{* *} \quad$ Reem M. AlMetrek ${ }^{* * *} \quad$ Lama M. Almania $^{* * *}$ \\ Department of Management, College of Business Administration, King Saud University, P.O. Box 71115, \\ Riyadh 11587, Saudi Arabia. \\ *nassani@ksu.edu.sa **Ranaalmusad@gmail.com \\ *** ReemAlMetrek@gmail.com **** Lmalmania@gmail.com
}

Abstract

\begin{abstract}
Burnout has a negative impact on organizational outcomes' efficiency and effectiveness, hence harming and threatening its survival. The present study investigated the impact of job stress and self-efficacy on job burnout dimensions. Participants in this research were 367 employees working in the private sector in Riyadh, Saudi Arabia. The data were collected by using a questionnaire consisting of four sections. The results showed a significant relationship between the three dimensions of job burnout. Also, the relationship between job stress and emotional exhaustion (EE) and depersonalization (DP) dimensions was positive, whereas the personal accomplishment (PA) dimension was negative. In contrast, self-efficacy showed a significant negative relationship with EE and DP dimensions and a positive relationship with PA dimension. Moreover, the study revealed a negative relationship between the independent variables, which are job stress and self-efficacy. In addition, the results of path analysis supported these findings.
\end{abstract}

Keywords: job burnout dimensions, job stress, self-efficacy, private sector, Saudi Arabia.

DOI: $10.7176 / \mathrm{EJBM} / 13-6-23$

Publication date:March $31^{\text {st }} 2021$

\section{Introduction}

Job burnout in the field of labor productivity has been an active issue that has been addressed by many practitioners and researchers. It does not only affect the individuals negatively, but it also costs the organizations in the United States approximately US\$50 to US\$75 million annually (Mardani, Mardani, 2014). No doubt that the human resources of an organization are one of its most valuable assets, and for an organization to achieve its goals, it has to manage its human resources effectively and efficiently. Job burnout and self-efficacy are some of the defining features of a person's relationship with a career (Leiter, 1992). A number of studies found that job burnout is a consequence of job stress, which is a significant factor in reducing efficacy in the workplace (Mardani, Mardani, 2014). In addition, job stress points to a poor fit between an individual's capabilities and their work environment (Jamal, 1984). To be more precise, no report has shown any positive outcomes of job burnout for employees, family/friends, employers, or society (Lambert, Qureshi, Frank, Klahm, \& Smith, 2018). So not only do these factors affect the individuals, but they also affect the organizations and society as a whole, which emphasizes their importance even more. While burnout represents a vital and one of the foremost frequently studied outcomes of job stress, self-efficacy is believed to protect workers from adverse job stress outcomes because it can modify their beliefs (Shoji et al., 2016).

The current study adds to the literature in many ways. First, there is a gap in literature regarding investigating the dimensions of job burnout based on job stress and self-efficacy among private sector employees in Saudi Arabia. Second, no published studies could be found that included job stress and self-efficacy in the same model as job burnout dimensions. Third, the study investigates the direct and indirect relationship between job stress, self-efficacy and job burnout. Finally, this study aims to examine the impact of job stress and self-efficacy on job burnout dimensions on employees in the private sector in Riyadh, Saudi Arabia. 


\section{Literature Review}

2.1 Theoretical Background and Hypotheses Development

\subsubsection{Job Burnout}

One of the most critical and expensive problems that HR has to deal with is burnout. Burnout was first introduced by the psychiatrist Freudenberger in 1975 (Maslach, Schaufeli, \& Leiter, 2001). It is defined as a psychological syndrome caused by excessive work resulting in feelings of emotional exhaustion, detachment, and lack of personal accomplishment (Maslach, 2003; Maslach \& Leiter, 1997; Maslach et al., 2001). Maslach \& Jackson (1981) suggested that burnout has three dimensions: emotional exhaustion (EE), depersonalization (DP), and a reduced sense of personal accomplishment (PA). When an individual feels emotionally worn out from work, it reflects on the EE dimension. DP is evident when a person treats others in a very negative way to create a space. The last dimension, reduced sense of PA, emerges when a person feels incapable of doing work (Maslach \& Jackson 1981; Maslach et al., 2001). Some research stated that burnout develops from chronic job stress, which occurs when the job requirements do not match the worker's perceived abilities (Shoji et al., 2016). Not only that, but also burnout has been found to be associated with many negative consequences on both individuals themselves and people around them in the organization. Some of the vital problems caused by burnout are depression, weak performance and absenteeism (Ali, Asad, \&Yousaf, 2019). In general, it is believed that job productivity and performance are impacted by job burnout (Bayani, \& Baghery, 2018). A study was done to analyze the three dimensions of job burnout by Rumschlag (2017) stated that male teachers, who endured EE might also become depersonalized. According to Tony \& Lilian (2002) EE that occurs due to environmental demands, increases DP. Based on the theoretical results, the first hypothesis of this study was developed as the following:

$\mathrm{H} 1$ : There is a positive relationship between EE and DP dimensions.

\subsubsection{Self-Efficacy and Job Burnout}

Self-efficacy is a concept that is frequently mentioned in relation to the human behavior and attitude. According to Albert Bandura (1994), the psychologist who first proposed the concept, self-efficacy can be defined as the extent to which one's personal judgement of their own capabilities can play a part in their ability to perform an action successfully. Additionally, he suggested that there are four main sources through which self-efficacy is developed. First, and the most effective source, mastery experiences. Success and failure in performing something can affect a person's self-efficacy greatly. Success would strengthen the sense of self-efficacy while failure would weaken it. Second, vicarious experiences. Seeing other people perform an action successfully would affect one's self-efficacy positively. Third, social persuasion, which is verbal encouragement. Being told that a person has what it takes would help them in overcoming self-doubt and improving their chances of succeeding. Lastly, psychological reactions. People's self-efficacy can be significantly affected by their reactions to situations, which include stress, negative emotional tendencies, and misinterpretations of physical states. How these reactions are perceived and interpreted has a great impact on their sense of self-efficacy as well as their health. For instance, people with a high sense of self-efficacy would view challenging situations as exciting and motivating while people with a low sense of self-efficacy would be anxious and weakened, which is why self-efficacy can influence people's lives and professional careers.

There are many studies and research papers that have linked self-efficacy to job burnout (Yulianti, Atomzeal, \& Arina, 2018; Çelik \& Kahraman, 2018; Shoji et al., 2016). According to these studies, when challenges arise, people with a high sense of self-efficacy usually make an effort and try to improve their situation. Contrarily, those with a low sense of self-efficacy tend to do the opposite, which would likely lead to job burnout. A study was done on the relationship between self-efficacy and job burnout by Savaş, Bozgeyik, \& Eser (2014), which confirmed that people with a low sense of self-efficacy experience job burnout more than their counterparts with a high sense of self-efficacy. Another study by Topuzov, Malykhin, Aristova, \& Shamne (2020) indicated that there is a cause-and-effect relationship between the high level of burnout and the low level of self-efficacy. Furthermore, the findings of a study by Gündüz (2012) stated that there is a strong negative relationship between self-efficacy and both EE and DP, and a significant positive relationship between self-efficacy and PA. Moreover, the research paper on Iranian teachers stated that there is a direct and indirect relationship with the three dimensions of job burnout. The researchers found that self-efficacy correlated negatively with EE and DP, but related positively with the third dimension of burnout, which is PA (Bayani, \& Baghery, 2018). Taking the theoretical studies into consideration, the following hypothesis was established as:

H2: There is a positive relationship between self-efficacy and PA, and a negative one between the other two dimensions of job burnout.

\subsubsection{Self-Efficacy and Job Stress}

Self-efficacy is considered to be the belief of the individual's ability to overcome difficult situations. When self-efficacy improves, it decreases job stress (Atai, \& Özyaral, 2021). Not to mention, self-efficacy plays 
a role in reducing the negative impact of job stress. There is an inverse correlation between job stress and selfefficacy, where the increase of skills decreases work pressure (Batool, Atta, \& Rize, 2020; Naoreen, Mohsin, \& Farooqi, 2020; Shin \& Kong 2017). Furthermore, the results of the study done by Alejandro, Michelle, Amy, \& Bettye (2017) found that there is a statistical relationship between job stress and self-efficacy. Therefore, the third hypothesis was formulated as:

H3: There is an inverse relationship between job stress and self-efficacy.

\subsubsection{Job Stress and Job Burnout}

Stress is the most frequent emotion we come across throughout the day, which has a negative impact on both our health and performance. It is a tense physical or emotional feeling that happens when the individual cannot respond to the pressures that are unmanageable (Ho, 2018). Researchers do not have a fixed definition for job stress. Vasan (2018) defined job stress as an employee's adverse physical and emotional reaction to job requirements being inconsistent with their competence and needs; hence ambiguous job assignments, lack of development, lack of promotion, and job insecurity cause stressful situations. Also, Lambert et al., (2018) defined it as an individual feeling difficulty, anxiety, concern, and depression related to work. According to the latest statistic done by Health and Safety Executive in Great Britain in 2020 regarding job stress, anxiety and depression, they found that the overall number of those cases was higher than the last period. It was almost 1,700/100,000 workers compared to 2,440/ 100,000 workers.

Also, there are many studies that linked the negative impact of job stress and job burnout in different industries. For example, the results of a study of student affairs professionals indicated a strong positive correlation between job stress and job burnout (Mullen, Malone, Denney, \& Dietz, 2018). Another study, done on police officers in India to test the impact of stress on the three dimensions of job burnout, showed a significant relationship between the increase of EE and the decrease of PA (Lambert et al., 2018). According to Guo et al., (2016), job stress positively affected the EE and DP dimensions of job burnout, and negatively affected the PA dimension in the staff nurses in China. Thus, the final hypothesis was explored in this study as the following:

H4: There is a direct and strong positive relationship between job stress and EE and DP dimensions and a strong negative relationship with AP.

\subsection{Research Model}

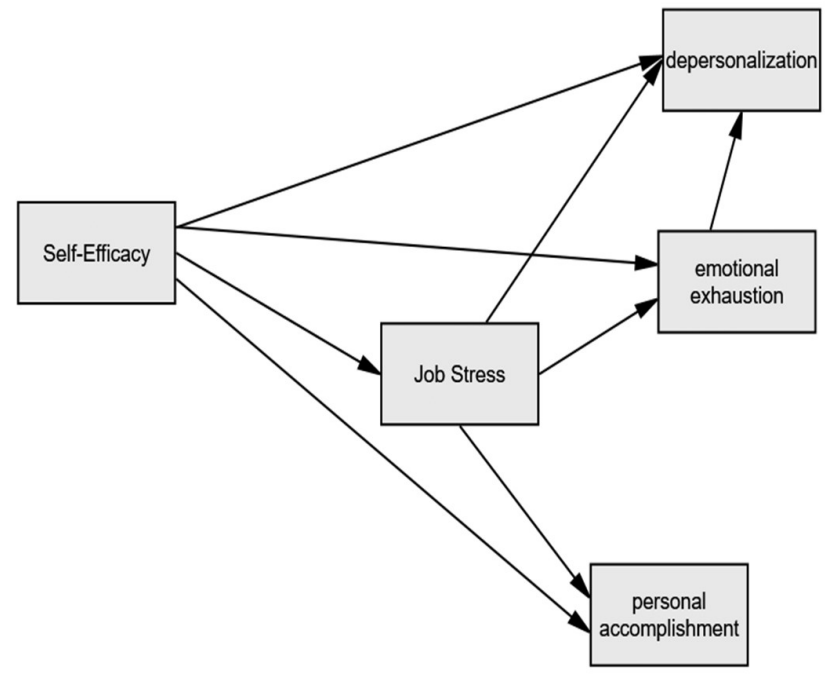

Figure I: Research Model

\section{Methodology}

\subsection{Participants}

This study was conducted in Riyadh, Saudi Arabia. The statistical population in this study includes all employees in the private sector in the capital city of Saudi Arabia. The statistic was dragged from the official website of the General Authority for Statistics, which is a Saudi government agency responsible for collecting, classifying, and analyzing statistical data from multiple sources. According to the last statistic of 2020, we chose 
a random sample that consists of 385 participants, and in which the sample size was determined using Richard Geiger's formula. However, to prevent skewed results, we excluded 18 participants due to the extreme values they displayed, which contradicted the scale purposes. So, the final sample size was 367 participants.

\subsection{Data Collection}

To collect the data for this study, a questionnaire was used, which consisted of three sections as well as the demographic data section. The questionnaire was shared with the sample size via google forms. The instruments used in the questionnaire are the following:

The Maslach Burnout Inventory scale was used to measure job burnout (Maslach \& Jackson, 1986). It is composed of 22 items that measure the three aspects of burnout: EE ( 9 items), DP ( 5 items), and decreased PA ( 8 items). The items are rated on a 5-point Likert scale ranging from 1 (never) to 5 (always). The high scores in EE and DP and low scores in PA indicate high level of burnout. In the current study, the Cronbach's alpha reliability coefficient for the entire questionnaire was .75. EE was .83, DP was .73, and PA was .82.

To measure employees' job-stress, a questionnaire developed by Parker \& De-Cotiis (1983) was used. There are 13 items in this questionnaire, and a 5-point Likert scale that ranges from 1 (strongly disagree) to 5 (strongly agree). The questionnaire consists of two scales, which are time stress and anxiety that an employee has perceived at work. The Cronbach's alpha value for this scale was .88 .

Employees' self-efficacy was measured using the New General Self-Efficacy Scale (NGSE) proposed by Chen, Gully, \& Eden (2001) which is an adapted version of the General Self-Efficacy Scale (SGSE) developed by Sherer et al., (1982). Although the NGSE scale is shorter, it demonstrated high reliability, and a higher predictive validity than the SGSE scale (Chen et al., 2001). It consists of 8 items, and a 5-point Likert scale that assesses a general sense of perceived self-efficacy, and in which $(1=$ strongly disagree; $3=$ neither agree nor disagree; $5=$ strongly agree). The Cronbach's alpha reliability coefficient for the scale was .87.

\subsection{Data Analysis}

The analysis in the research has been carried out using the Statistical Package for the Social Sciences (SPSS) version 26 and Analysis of Moment Structures (AMOS) version 26. At the first stage of analyzing the data, it is checked for inconsistent responses. Then, correlation variables were computed for correlations between quantitative variables. Regression analyses were performed on all variables, then a path analysis technique was utilized to determine the best model fit.

\section{Results}

\subsection{Job Burnout Dimensions}

A correlation test utilized all three dimensions of job burnout, and all three were correlated. EE dimension was positively correlated with DP $P<.001$, and negatively with PA $P=.01$. In the same way, DP was negatively correlated with PA $P=.01$.

\subsection{Self-Efficacy and Job Burnout}

The correlation between self-efficacy and the three dimensions of job burnout was tested and yielded significant correlations. Both EE and DP dimensions had a negative correlation with $P<.001$ and $P=.007$ respectively. However, the PA dimension had a positive correlation with $P<.001$.

\subsection{Self-Efficacy and Job Stress}

Self-efficacy and job stress were significantly negatively correlated with $P=.03$. 


\subsection{Job Stress and Job Burnout}

The correlation between job stress and the three dimensions of job burnout was tested and yielded significant correlations. Both EE and DP dimensions had a positive correlation with $P<.001$. However, the PA dimension had a negative correlation with $P<.001$.

Table 1 Summary of Correlations, Means, and Standard Deviation for Scores on the Job Burnout, Job Stress and Self-Efficacy

\begin{tabular}{|c|c|c|c|c|c|c|}
\hline Variables & $\mathrm{EE}$ & DP & PA & Job Stress & M & SD \\
\hline $\mathrm{EE}$ & & & & & 2.86 & .72 \\
\hline DP & $.36^{* *}$ & & & & 2.08 & .80 \\
\hline PA & $-.14 * *$ & $-.13 *$ & & & 3.52 & .70 \\
\hline Job Stress & $.55^{* *}$ & $.37 * *$ & $-.24 * *$ & & 3.28 & .81 \\
\hline Self-Efficacy & $-.19 * *$ & $-.14 * *$ & $.40 * *$ & $-.11 *$ & 4.11 & .63 \\
\hline
\end{tabular}

EE, Emotional Exhaustion; DP, Depersonalization; PA, Personal Accomplishment. $* p<.05$, two-tailed. ${ }^{* *} p$ $<.01$, two-tailed.

\subsection{Job Stress, Self-Efficacy and Job Burnout Dimensions}

A linear regression analysis was done between the three job burnout dimensions, and both job stress and self-efficacy, which resulted in three significant regression models. The first regression model for EE dimension was significant $\left[R^{2}=.32, F(2,364)=85.28, P<.001\right]$ with both job stress and self-efficacy. The second regression model for DP dimension was significant $\left[R^{2}=.15, F(2,364)=31.03, P<.001\right]$ with both independent variables. The final regression model for PA dimension was significant $\left[R^{2}=.20, F(2,364)=44.06, P<.001\right]$ with job stress and self-efficacy.

Table 2 EE Dimension and Job Stress and Self-Efficacy

\begin{tabular}{llccc}
\hline Model & $B$ & $\beta$ & $t$ & $P$ \\
\hline Job Stress & .48 & .54 & 12.31 & $<.001$ \\
Self-Efficacy & -.15 & -.13 & -2.96 & .003 \\
\hline
\end{tabular}

EE, Emotional Exhaustion

Table 3 DP Dimension and Job Stress and Self-Efficacy

\begin{tabular}{lllll}
\hline Model & $B$ & $\beta$ & $t$ & $P$ \\
\hline Job Stress & .35 & .36 & 7.32 & $<.001$ \\
Self-Efficacy & -.13 & -.10 & -2.09 & .037 \\
\hline
\end{tabular}

DP, Depersonalization

Table 4 PA Dimension and Job Stress and Self-Efficacy

\begin{tabular}{lllll}
\hline Model & $B$ & $\beta$ & $t$ & $P$ \\
\hline Job Stress & -.17 & -.20 & -4.13 & $<.001$ \\
Self-Efficacy & .42 & .38 & 7.92 & $<.001$ \\
\hline
\end{tabular}

PA, Personal Accomplishment 


\subsubsection{Research Model Fit Using Path Analysis}

Path analysis was utilized to check the study's hypotheses, which resulted in the default model to be the perfect fit for goodness fit. Fit indices from the default model $\left[\chi^{2}=1.338 P=.512, \chi^{2} / \mathrm{df}=0.669 \mathrm{RMSEA}=.000\right.$, $\mathrm{CFI}=1.000$, GFI $=.999$, $\mathrm{AGFI}=.989$, and $\mathrm{NFI}=.995]$.

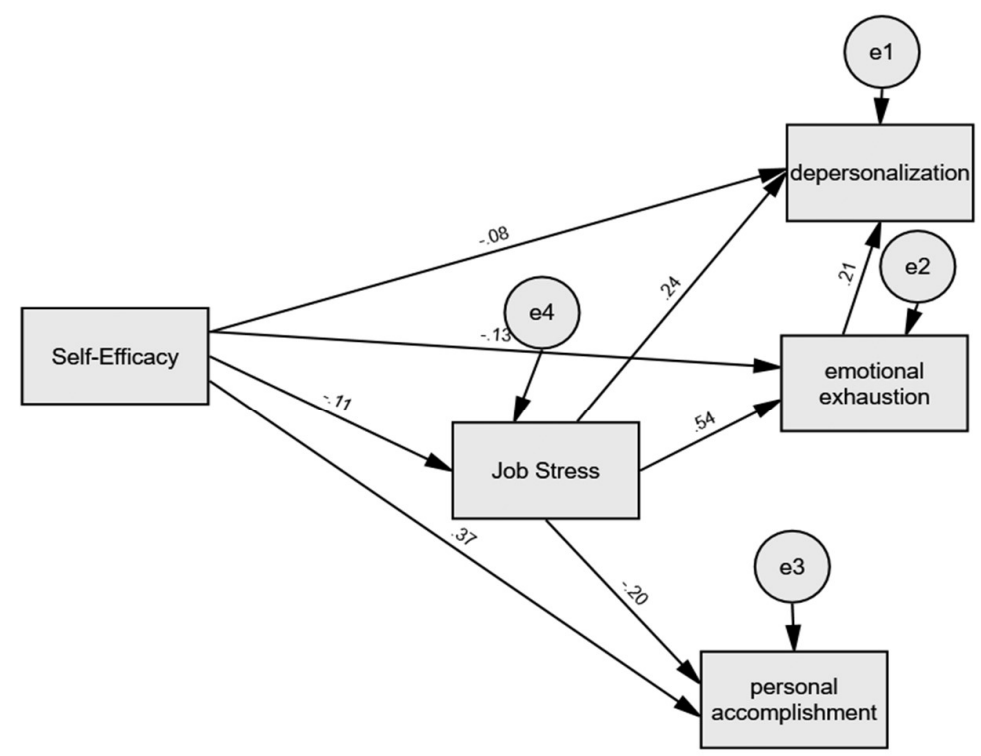

Figure 2 Path Analysis

Table 5 The Fit Indices of Default Model

\begin{tabular}{lllllllll}
\hline Model & $\chi^{2}$ & df & $\chi^{2} / \mathrm{df}$ & RMSEA & CFI & GFI & AGFI & NFI \\
\hline Default Model & 1.338 & 2 & 0.669 & .000 & 1.000 & .999 & .989 & .995 \\
\hline
\end{tabular}

RMSEA, Root Mean Square Error of Approximation; CFI, Comparative Fit Index;

GFI, Goodness-of-fit; AGFI: Adjusted goodness-of-fit; NFI, Normed-fit index

\subsubsection{Path Coefficients in Default Model}

Path Coefficients analyses showed similar results to the linear regression analysis, where self-efficacy had a negative direct effect with job stress and both EE and DP dimensions, but a positive direct effect on PA dimension. Nevertheless, job stress showed a positive direct effect with all variables except PA dimension, which was negative. Finally, EE dimension revealed a positive direct effect with DP dimension.

Table 6 Standardized Direct, Indirect, and Total Effects in the Default Model

\begin{tabular}{llllllllll}
\hline \multirow{2}{*}{ Variables } & \multicolumn{3}{l}{ Self-Efficacy } & \multicolumn{3}{c}{ Job Stress } & \multicolumn{3}{c}{ EE } \\
\cline { 2 - 11 } & D.E. & I.E. & T.E. & D.E. & I.E. & T.E. & D.E. & I.E. & T.E. \\
\hline Job Stress & -.11 & .000 & -.11 & .000 & .000 & .000 & .000 & .000 & .000 \\
EE & -.13 & -.06 & -.19 & .54 & .000 & .54 & .000 & .000 & .000 \\
DP & -.07 & -.07 & -.14 & .25 & .11 & .36 & .21 & .000 & .21 \\
PA & .38 & .02 & .40 & -.20 & .000 & -.20 & .000 & .000 & .000 \\
\hline
\end{tabular}

EE, Emotional Exhaustion; DP, Depersonalization; PA, Personal Accomplishment; D.E., Direct Effect; I. E., Indirect Effect; T. E., Total Effect 


\section{Discussion}

The aim of this study was to investigate the impact of job stress and self-efficacy on job burnout dimensions among employees in the private sector in Riyadh, Saudi Arabia. The study found a significant relationship between the three dimensions of job burnout, where EE and PD were positively related, and PA was negatively related. These findings support the first hypothesis, which is consistent with the other studies that examined job burnout. Maslach, \& Jackson (1981) argued that when an individual feels emotionally exhausted from work, that reflects positively on the EE and DP dimensions, and negatively on the last dimension, which is PA. Also, Rumschlag (2017) concluded that high levels of EE can lead to depersonalization. Moreover, Tony \& Lilian (2002) stated that environmental demands that trigger EE could increase DP.

Self-efficacy revealed a significant negative relation with EE and DP dimensions, and a positive relationship with PA dimension. In the same manner, the regression models of the three dimensions of job burnout with self-efficacy showed similar outcomes. This is consistent with the results of a previous study by Bayani, \& Baghery (2018). Topuzov et al., (2020) pointed out that high level of burnout and low level of self-efficacy have a cause-and-effect relationship. Further, self-efficacy and EE and DP dimensions have a strong negative relationship while self-efficacy and PA have a positive relationship (Gündüz, 2012).

The independent variables, which are job stress and self-efficacy, were negatively related. This supports the assertion that there is a negative relationship between job stress and self-efficacy. Hence, a person with high level of self-efficacy would be more prone to deal with work stress effectively. Therefore, self-efficacy is a convenient way of measuring job stress (Alejandro et al. 2017; Batool et al., 2020; Naoreen et al. 2020).

Finally, like the regression model results, the relationship between job stress and the job burnout dimensions showed a high positive connection with EE and DP dimensions, and a negative connection with PA dimension. Mullen et al. (2018) stated that there is a strong positive relationship between job stress and job burnout. Job stress impacts EE and DP positively; however, it impacts PA negatively (Guo et al., 2016).

\subsection{Strengths \& Limitations}

This study was designed with the goal of identifying the connection between job burnout dimensions, and both job stress and self-efficacy. The focus of this study was one of its strengths, especially since this is a new field of investigation in Saudi Arabia and could open up new possibilities and opportunities. Another strength was that the study did not rely on free-form self-reporting to collect data from subjects, but rather used standardized assessments of the job burnout, job stress and self-efficacy to collect responses. However, out of the 385 participants' responses, 18 were discarded due to their inconsistency and use of extreme values, which is incompatible with the scale's purposes.

\subsection{Implications}

The importance of this study in the field of labor is to prevent employees' job burnout and its consequences. Hence, the human resources department could periodically assess the employees' self-efficacy to reduce the probability of developing job stress and job burnout. Since self-efficacy can affect job stress, employers should utilize that, and enhance employees' self-efficacy. There are many methods to enhance the self-efficacy of the employees, which can range from simple yet effective practices such as observing role models deal with difficult situations successfully and sending the employees motivational notes that are designed to enhance selfefficacy, to organizational interventions such as job enrichment, job enlargement, and relevant training (Jackson, 2002; Parker, 1998).

\subsection{Recommendations}

While taking into consideration the implications of this study, further research is recommended in this area. It is also recommended to use other methods to investigate the impact of self-efficacy on job stress and job burnout as well as conducting programs that are designed to increase self-efficacy and measure their effects on job burnout and job stress. Researching how to increase employees' self-efficacy and to ensure its stability seems to be a very important area. To make more generalizable inferences, more studies should be done using both qualitative and quantitative methods. In addition, future studies should consider different methods to measure the self-efficacy variable more accurately. Including bigger geographical areas is recommended, too. 


\section{Conclusion}

Job burnout is found in literature to be an outcome of high levels of job stress and low levels of selfefficacy (Shoji et al., 2016). In this study, the relationships between job burnout dimensions, job stress and selfefficacy were investigated. Employees with higher levels of job stress are more likely to develop job burnout whereas employees who score higher on self-efficacy are less likely to show signs of job burnout. These findings could save organizations a lot both financially and emotionally as preventing job burnout is more effective than dealing with its consequences.

\section{References}

Alejandro, G., Michelle L. P., Amy O., \& Bettye G. (2017) The influence of high-stakes testing on teacher selfefficacy and job-related stress, Cambridge Journal of Education, 47:4, 513-531, DOI: 10.1080/0305764X.2016.1214237

Ali, H. G., Asad, M., Yousaf, M. (2019). Supervisor Incivility and Turnover Intentions with the Mediating Role of Job Burnout and Moderation of Job Performance. NUML International Journal of Business \& Management, 14(1), 1-13.

Atai, G., \& Özyaral, O. (2021). Study on Factors Affecting Accountants Job Stress: Focusing On Self-Efficacy, Job Satisfaction and Work Engagement. Revista Argentina de Clínica Psicológica, 587-595, DOI: $10.24205 / 03276716.2020 .2055$

Bandura, A. (1994). Self-efficacy. Encyclopedia of Human Behavior, 4, 71-81.

Batool, S., Atta, M., \& Riaz, N. (2020). Impact of self-efficacy on job stress in teachers: The role of marital status. Journal of Research in Social Sciences, 8(2), 46-55.

Bayani, A. A., \& Baghery, H. (2018). Exploring the Influence of Self-Efficacy, School Context and Self-Esteem on Job Burnout of Iranian Muslim Teachers: A Path Model Approach. Journal of Religion and Health, 59(1), 154162. https://doi.org/10.1007/s10943-018-0703-2

Çelik, O.t., \& Kahraman, Ü. (2018). The relationship among teachers' general self-efficacy perceptions, job burnout and life satisfaction. Universal Journal of Educational Research, 6(12), 2721-2729.

Chen, G., Gully, S. M., \& Eden, D. (2001). Validation of a new general self-efficacy scale. Organizational Research Methods, 4(1), 62-83.

General Authority for Statistics. (2020). Labor market statistics Q3 2020 [pdf]. Retrieved from https:/www.stats.gov.sa/sites/default/files/LM_Q3\%202020\%20\%28Press\%20release_EN\%20\%29_1.pdf

Gündüz, B., (2012). Self-efficacy and burnout in professional school counselors. Educational Sciences: Theory and Practice, 12, 1761-1767.

Guo, J., Chen, J., Fu, J., Ge, X., Chen, M., \& Liu, Y. (2016). Structural empowerment, job stress and burnout of nurses in China. Applied Nursing Research, 31, 41-45. https://doi.org/10.1016/j.apnr.2015.12.007

Health and Safety Executive. (2020). Work-related stress, anxiety or depression statistics in great britain, 2020 [pdf]. Retrieved from https://www.hse.gov.uk/statistics/causdis/stress.pdf

Ho, T. (2018). ROLE STRESS AND JOB BURNOUT OF SCHOOL COACHES: USING SOCIAL SUPPORT AND SELF-EFFICACY AS MODERATORS. International Journal of Organizational Innovation (Online), 10(3), 266-284.

Jackson, J. W. (2002). Enhancing self-efficacy and learning performance. The Journal of Experimental Education, $70: 3,243-254$. 
Jamal, M. (1984). Job stress and job performance controversy: An empirical assessment, Organizational Behavior and Human Performance, 33, 1-21.

Lambert, E. G., Qureshi, H., Frank, J., Klahm, C., \& Smith, B. (2018). Job Stress, Job Involvement, Job Satisfaction, and Organizational Commitment and Their Associations with Job Burnout Among Indian Police Officers: A Research Note. Journal of Police and Criminal Psychology, 33(2), 85-99. https://doi.org/10.1007/s11896-017-9236-y

Leiter, M. P. (1992). Burn-out as a crisis in self-efficacy: Conceptual and practical implications, Work \& Stress, $6(2), 107-115$.

Mardani, S., Mardani, N. (2014). The Impact of Psychological Empowerment on Job Burnout in Hospital Staff. International Journal of Hospital Research, 3(2), 69-78.

Maslach, C. (2003) Job burnout: new directions in research and intervention. Curr Dir Psychol Sci 12:189-192

Maslach, C., \& Jackson, S. (1981). The measurement of experienced burn-out. Journal of Occupational Behavior, $2,99-113$

Maslach, C., \& Leiter, M.P. (1997). The truth about burnout. San Francisco: Jossey-Bass.

Maslach, C., Schaufeli, W. B., \& Leiter, M. P. (2001). Job burnout. Annual Review of Psychology, 52, $397-422$. doi:10.1146/annurev.psych.52.1.397

Mullen, P. R., Malone, A., Denney, A., \& Dietz, S. S. (2018). Job Stress, Burnout, Job Satisfaction, and Turnover Intention Among Student Affairs Professionals. College Student Affairs Journal, 36(1), 94-108. https://doi.org/10.1353/csj.2018.0006

Naoreen, B., Mohsin, M. N., \& Farooqi, S. M. A. (2020). University Teachers' Perceptions of Self-Efficacy and Its Relationship with Workplace Stress. Global Social Sciences Review, 5(2), 182-189. https://doiorg.sdl.idm.oclc.org/10.31703/gssr.2020(V-II).17

Parker, D.F., DeCotiis, T.A (1983). Organizational Determinants of Job Stress. Organizational Behavior and Human Performance, 32(2), 160-177.

Parker, S. K. (1998). Enhancing role breadth self-efficacy: The roles of job enrichment and other organizational interventions. Journal of Applied Psychology, 83(6), 835-852.

Rumschlag, K. E. (2017). Teacher burnout: A quantitative analysis of emotional exhaustion, personal accomplishment, and depersonalization. International Management Review, 13(1), 22-36,101.

Savaş, A., Bozgeyik, Y., \& Eser, İ. (2014). A study on the relationship between teacher self efficacy and burnout. European Journal of Educational Research, 3, 159-166.

Sherer, M., Maddux, J. E., Mercandante, B., Prentice-Dunn, S., Jacobs, B., \& Rogers, R. W. (1982). The selfefficacy scale: Construction and validation. Psychological Reports, 51(2), 663-671.

Shin, H., \& Kong, H. (2017). Research on job stress, psychological well-being and coping resources of fire officials: Focusing on the mediating effects of self-efficacy and social support. International Information Institute (Tokyo). Information, 20(8), 6103-6110.

Shoji, K., Cieslak, R., Smoktunowicz, E., Rogala, A., Benight, C. C., \& Luszczynska, A. (2016). Associations between job burnout and self-efficacy: A meta-analysis. Anxiety, Stress, \& Coping, 29(4), 367-386. https://doi.org/10.1080/10615806.2015.1058369

Tony, T. S., \&amp; Lilian, M. (2002). Emotional exhaustion, DEPERSONALISATION, and personal ACCOMPLISHMENT - the case of BURNOUT among school social workers in Hong Kong. Asia Pacific Journal of Social Work and Development, 12(2), 76-94. doi:10.1080/21650993.2002.9755901 
Topuzov, O. M., Malykhin, O. V., Aristova, N. O., \& Shamne, A. V. (2020). Optimization of university department management: the increase of foreign language teachers' self-efficacy by preventing job burnout. The New Educational Review, 59, 59-71.

Vasan, M. (2018). Impact of job stress on job satisfaction among the pharmaceutical sales representatives. Research Journal of Pharmacy and Technology, 11(9), 3759-3764. doi:http://dx.doi.org.sdl.idm.oclc.org/10.5958/0974-360X.2018.00688.1

Yesilbas, M., \& Wan, T. T. (2017). The impact of mobbing and JOB-RELATED stress on burnout and HEALTHRELATED quality of Life: The case of TURKISH TERRITORIAL state representatives. International Journal of Public Administration, 40(12), 1024-1035. doi:10.1080/01900692.2016.1204553

Yulianti, P., Atomzeal, M. O., \& Arina, N. A. (2018). Burnout, self-efficacy and work satisfaction among special education teacher. KnE Social Sciences, 2018, 1180-1191. 